\title{
events guide
}

\section{CHRONICLING CONTEMPORARY CONFERENCECULTURE}

\section{How have scientific conferences changed since Nature was founded 150 years ago? By Virginia Gewin}

\section{P} articipation in scientific conferences has ballooned since Nature's founding in 1869 . Around 24,000 attendees from 113 countries were at the 2018 American Geophysical Union's Fall Meeting in Washington DC, for example. By contrast, fewer than 2,000 tickets were sold to spectators and presenters at the 1869 meeting of the British Association for the Advancement of Science, held in Exeter, UK.

Not surprisingly, the diversity of scientists has also changed in that time, as has recognition of the environmental impact of such large gatherings. Today's conference organizers are constantly taking steps to make sure that meetings are inclusive, safe and socially responsible.

To set the scene, Nature spoke to a science historian who reflects on an early series of UK meetings that began almost 190 years ago. We then hear from some of today's conference organizers, who outline a range of current concerns and how to handle them - including codes of conduct, offsetting carbon emissions, recognizing gender pronouns and overcoming visa hurdles.

\section{ALEXCSISZAR THE 1869 CONFERENCE VIBE}

The largest regular scientific conferences in around 1869 were probably those held by the British Association for the Advancement of Science (BAAS, now the British Science Association), founded in 1831. These were modelled on a format first used by German scientists in the 1820 s that had been picked up by scientific organizations. In the early to mid-nineteenth century, there was an outcry about how hard it was to make a living as a scientist, so the BAAS conference was predominantly about making science more accessible to the public. Its founders thought that if the public was interested in science, the British government might be inclined to offer more funding.
According to Gentlemen of Science, a 1981 bookby science historians Arnold Thackray and Jack Morrell, the events hosted 1,000 or more spectators. The intention was for attendees to have a good time, forge alliances and establish research collaborations. To include as many participants as possible and circumvent travel limitations, the conference moved to a different British city each year. This was an early attempt to be inclusive - at least for the mostly white middle- and upper-class men who attended.

To help to raise the profile of British science, experts were courted to come to the meeting to discuss hot topics in science, sometimes from as far away as the United States and South America. Many spectators attended these high-profile talks (similar to today's plenary speeches), and there could be hundreds of papers presented in the accompanying sectional meetings. These were dedicated to specialist branches of science, including mathematics, geology and zoology.

Abstracts of interest were written up in newspapers and periodicals, such as the weekly literary magazine The Athenaeum (published from 1828 until 1921) and, later, in Nature. (The botanist Joseph Hooker, who worked at the Royal Botanical Gardens at Kew near London, suspected that Nature would fail because it was trying to do what The Athenaeum already did.) If you were an elite scientist and you wanted international colleagues to know about your research, you might aim to get your paper covered in The Athenaeum because readers often passed their copies on to others. That meant reports of your work were likely to travel overseas faster than papers in what we'd now call primary researchjournals. And even if a scientist didn't attend a conference in person, they might ask someone else to read out their abstract to improve the chances of it getting covered.

Officially, women were banned from the sectional meetings until 1839 because of blatant sexism, but in practice they often attended. The conferences were large affairs, and women helped to make them a success

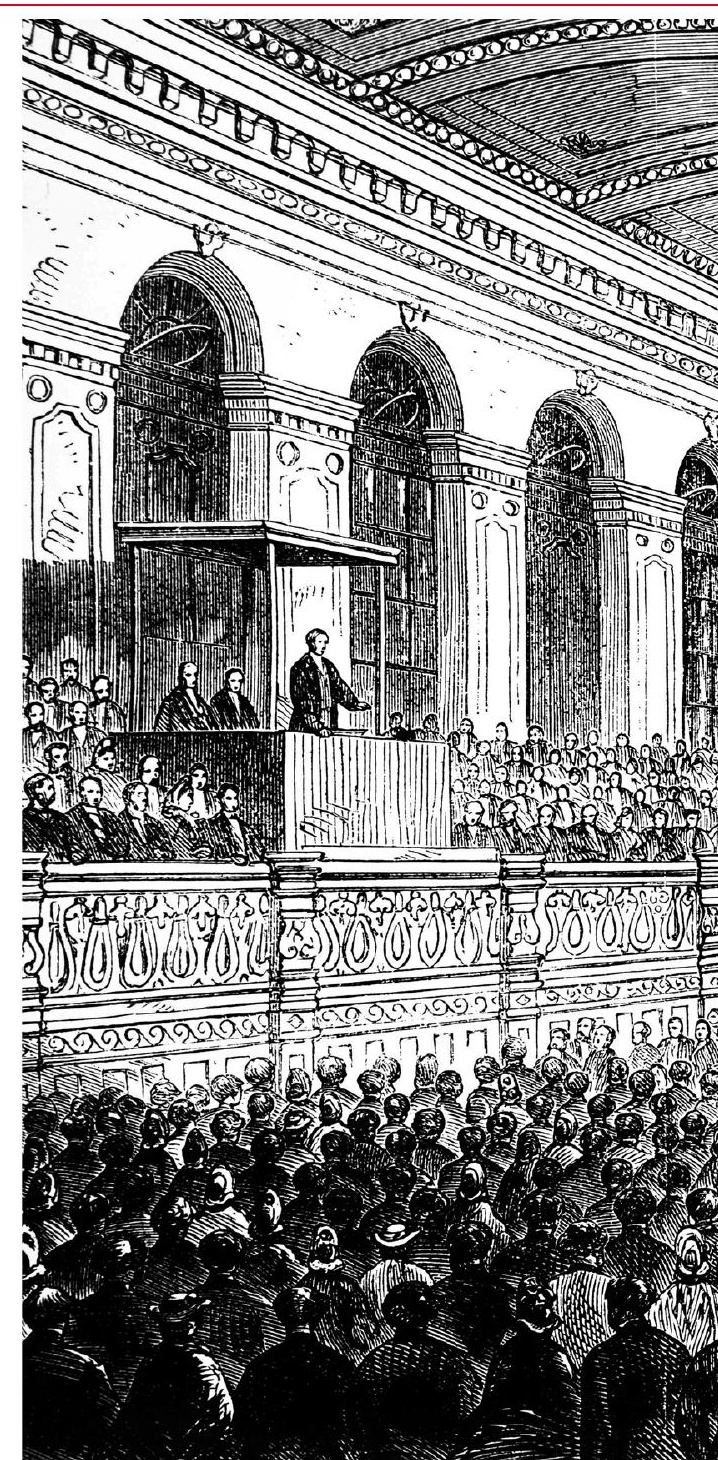

- both financially (because male members of the BAAS were allowed to buy extra tickets for women accompanying them to the meeting) and socially (because women were seen as providing cohesion for social activities

\section{"The conferences were large affairs, and women helped to make them a success - both financially and socially."}

outside the formal sessions). Women rarely gave talks at BAAS meetings during its first years, but some did, most often in the fields of statistics and economics.

Alex Csiszar is a science historian at Harvard University in Cambridge, Massachusetts. 


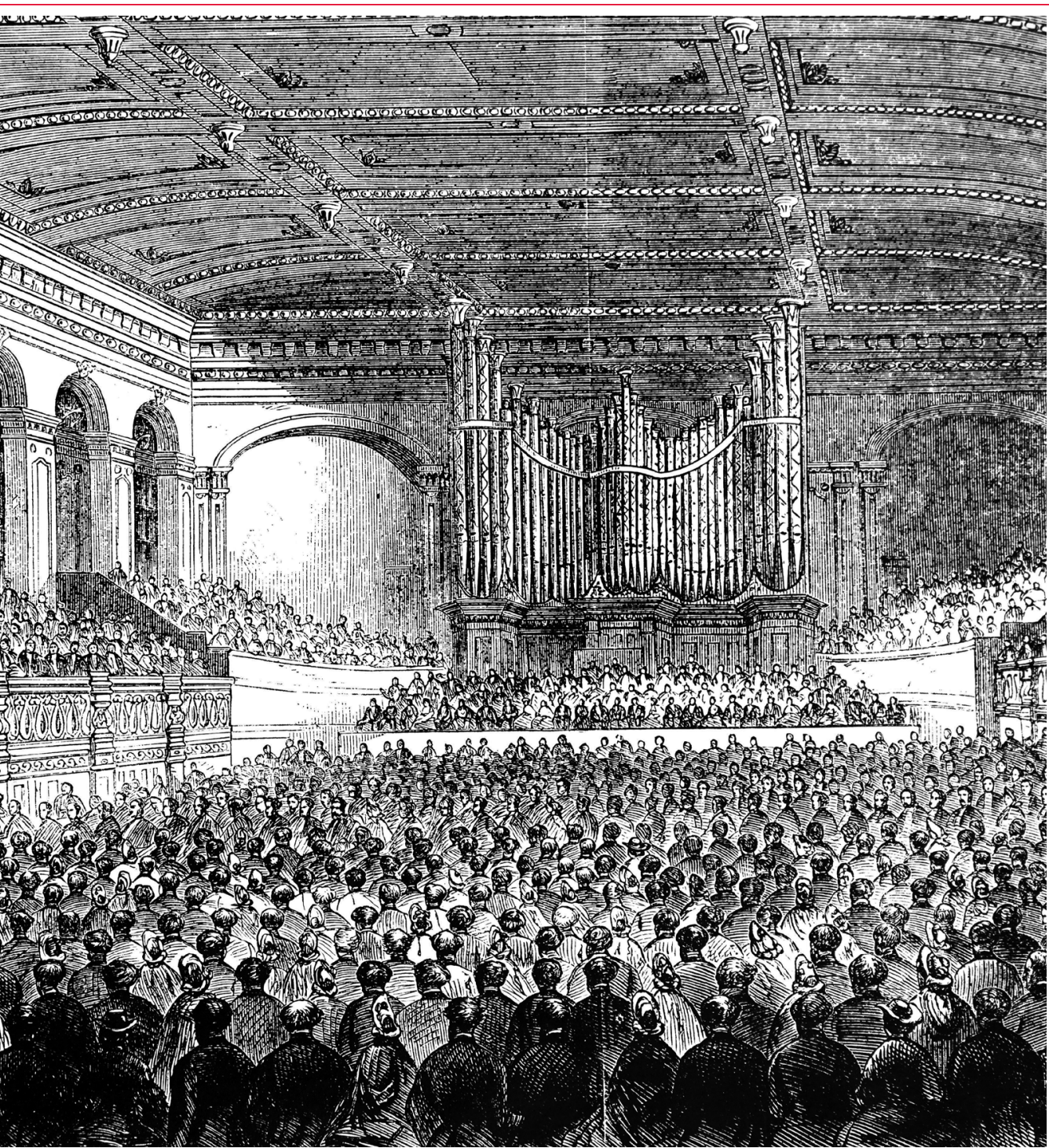

The British Association for the Advancement of Science held large conferences from 1831.

\section{ANDREACASE CODEOFCONDUCT}

In early 2017, the organizers of an annual evolution meeting got together to address concerns about how to handle inappropriate behaviour at conferences - whether sexual or gender harassment, exclusion or discrimination. For our meeting that June, held jointly by the Society for the Study of Evolution, the American Society of Naturalists and the Society of Systematic Biologists, we established a formal code of conduct. Because it was a new policy, conference attendees had to agree to it when registering for the meet ing. Unfortunately, I think a lot of people just clicked 'accept' on the form and didn't read the policy thoroughly.

The harder part, we discovered, was what to do if someone violated the code. And we hadn't publicized the fact that there was an official procedure for reporting inappropriate behaviour, so one of the three reports of codeof-conduct violations at the 2017 meeting was made through Twitter.

After the meeting, we set up a special committee to help us ensure that we have robust, enforceable procedures that are well publicized. We hired a harassment-prevention consultant and created a web resource called SAFE Evolution (see go.nature.com/2e9y1sg). It is modelled on a similar initiative by the American Geophysical Union, and details types of inappropriate behaviour, procedures for reporting a violation of the code of conduct, and transparency reports from our meetings.

The following meeting, in 2018, was held jointly with the European Society for Evolutionary Biology, and its representatives hadn't thought about a code of conduct. Culturally, it was a bit different. Some people initially didn't share our concerns, whereas others thought it was a great idea. Together,we agreed to have an external safety officer, who was not affiliated with our field, to receive reports of inappropriate behaviour. We always try to make sure that it doesn't feel like we are policing attendees, but that they still feel safe. At this year's meeting in Providence, Rhode Island, we also had 23 people dotted around the conference wearing huge badges. That meant they were identifiable to participants, and could offer assistance to those deciding whether to report a violation.

Making the code of conduct about all types of inappropriate behaviour keeps the focus on broader efforts to increase inclusivity. If you just concentrate on gender and sexual harassment, it tends to focus efforts on male harassers and female targets. We had nine reports this year. Although none was a report of clear sexual harassment, some participants said inappropriate things to others. The more often we can take reports and have conversations about inappropriate behaviour, the less likely such behaviour is to happen.

Andrea Case is executive vice-president of the Society for the Study of Evolution and an evolutionary biologist at Kent State University in Kent, Ohio.

\section{SUSANNEBUITER GREENTHEMEETINGS}

With more than 16,000 participants, the General Assembly of the European Geosciences Union (EGU) is the largest geoscience conference in Europe. As researchers who are keenly aware of environmental concerns, we realized that the flights and hotel stays for the conference, held each year in Vienna, yielded significant carbon dioxide emissions.

In 2018, for the first time, our registration process offered a voluntary contribution to offset carbon emissions. To calculate the amount to donate, a registrant could tick a box that said where they were travelling from. We raised nearly $€ 17,000$ (US $\$ 18,800$ ), which we gave to an anti-deforestation project in Brazil. In 2018, 32\% of participants donated to the offset fund. This year it went down to $25 \%$ - a decrease due, at least in part, to the fact that many institutes now already offset their staff members' travel emissions. In October, the EGU announced that it will offset travel emissions for every General Assembly participant at future meetings.

For us, it's part of a bigger attempt to make 


\section{events guide}

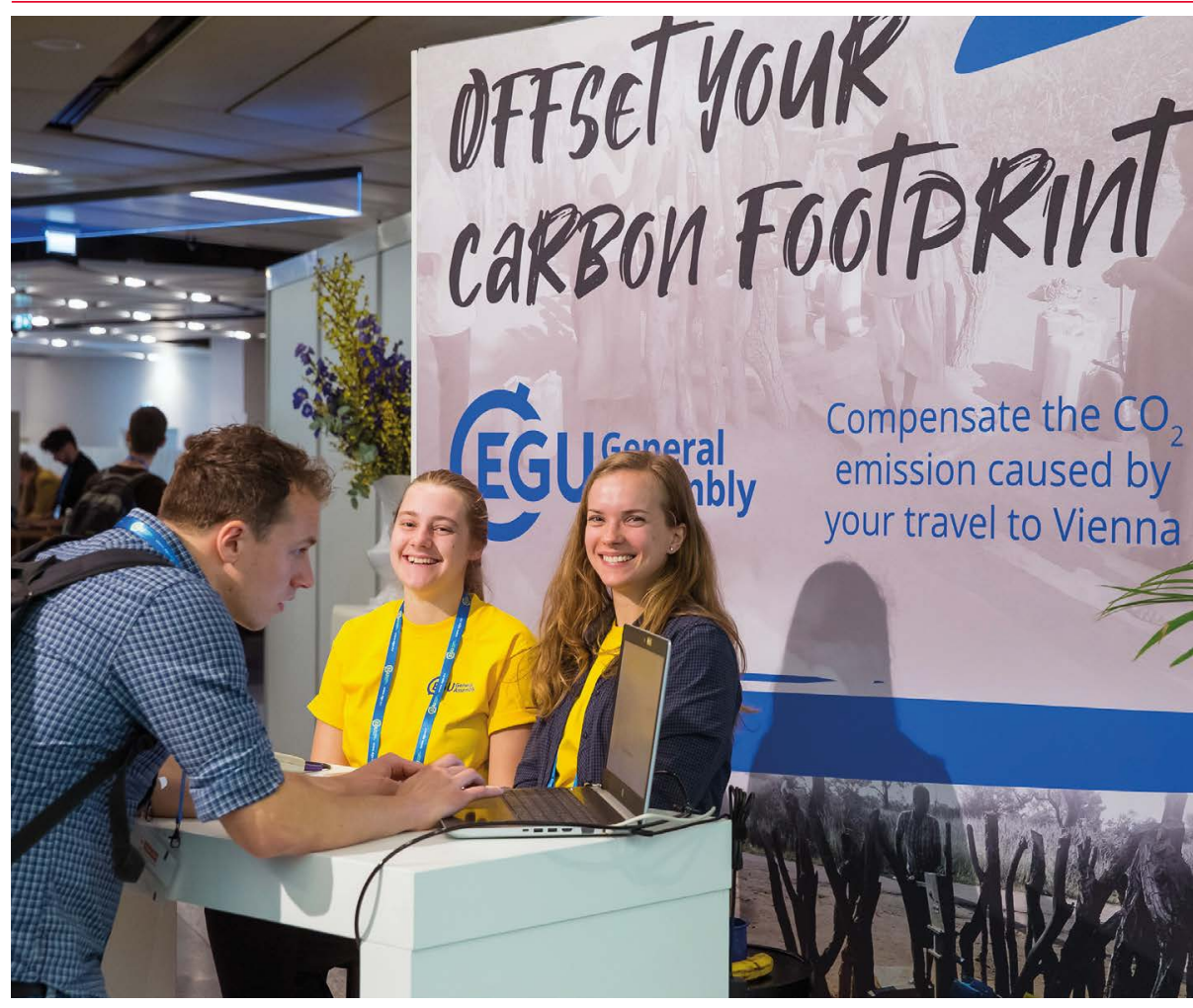

From 2020, the European Geosciences Union will offset emissions for assembly attendees.

our meetings greener. We have reduced paper use considerably by getting rid of the physical programme book. To reduce plastic, we have water fountains and ask attendees to bring their own bottles. Next year, we will ask people to bring their own coffee mugs.

To discourage unnecessary duplicate travel, we also recommend that attendees who have other business with conference participants book a small meeting hall for free. And we are exploring how to accommodate remote participation using web streaming.

Susanne Buiter is a programme chair at the European Geosciences Union and a solid-Earth geologist with the Geological Survey of Norway.

\section{SARAHMILLER IDENTIFYGENDERPRONOUNS}

There has been a big shift in the past five years in how we talk about gender diversity. There are many different ways to be gendered and it is important to make sure we don't misgender people. For roughly the past decade, the annual American Sociological Association (ASA) conference, our field's biggest event, has encouraged attendees to write their preferred pronouns on their badges. However, cisgender people (those whose gender identity matches the sex they were assigned at birth) often don't participate. That creates a problem because it further alienates those who do take part. When everyone states their preferred pronouns, it's more equitable for all.

Working with the ASA, our committee helped to institutionalize pronoun selection - we

\section{"When everyone states their preferred pronouns, it's more equitable for all."}

asked attendees to designate their preferred pronouns as part of last year's registration process, which were then printed on their badges. At the last conference, the options were limited to she/her, he/him, they/them, ze/zir or ze/ hir. Ideally, it's best to include an open-ended option that allows the registrant to add any other preferred pronouns. Everyone has the ability to opt out, but it shouldn't be the default.

There are radical changes occurring in the number of people openly identifying under the trans umbrella. And younger people are more likely than older ones to identify as transgender or non-binary. The sooner conferences get on board with these shifts, the better.

Sarah Miller is the American Sociological Association's member on the Sociologists for Trans Justice committee on promoting inclusion at conferences, and a sociologist at Boston University, Massachusetts.

\section{RICHARDHUGANIR REMOTEPARTICIPATION}

Getting visas in general is a slow, bureaucratic process. But to my knowledge, it wasn't a huge deal until the introduction of the 2017 travel ban, which denies individuals from several Muslim-majority countries entry to the United States. Around 30-40\% of members of the Society for Neuroscience (SfN) are international. We have an obligation to them. The expansion of neuroscience and international brain-research initiatives make the field a more collaborative environment.

During my year-long tenure as president of the SfN from November 2017, the immigration issue became a big deal. It has also become tougher to get a visa for those in China or Mexico, for example. Members were upset that researchers from certain countries who submitted abstracts couldn't come to the meeting. Some students from places such as Iran who were travelling from other countries not affected by the ban were also prevented from getting visas.

For the first couple of years, we tried to provide letters of support for visas. Once the immigration ban went into effect, some individuals had to cancel their trips to the meeting. We decided to encourage those people who couldn't get visas to present remotely: accommodations we made under the Science Knows No Borders programme (see go.nature.com/2ycteds).

We had around ten remote presenters at this year's conference, including some who provided pre-recorded Powerpoint presentations. Remote poster presenters were encouraged to conduct an online chat to allow meeting attendees to ask questions. I've never heard of other societies doing this. Although some remote presenters expressed disappointment about the limited feedback and engagement they received, this was the programme's first year, so the $\mathrm{SfN}$ will learn from the experience and try to improve it next year.

Richard Huganir is a former president of the Society for Neuroscience and a neuroscientist at Johns Hopkins University in Baltimore, Maryland.

\section{Interviews by Virginia Gewin.}

Interviews have been edited for length and clarity. 